\title{
International Federation for Emergency Medicine Model Curriculum for Continuing Professional Development
}

Cherri Hobgood, MD*; Terrence Mulligan, DO ${ }^{\dagger}$; Gautam Bodiwala, MD; Peter Cameron, MD ;

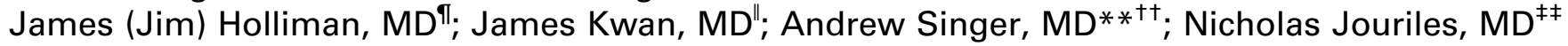

Keywords: Curriculum, Emergency Medicine, Professional, Training, Education, CMD - Continuous Professional

Development, $\mathrm{CME}$ - Continuing Medical Education

\section{BACKGROUND}

The International Federation of Emergency Medicine (IFEM) mission is to improve emergency medicine (EM) around the world. Central to this philosophy is specialty development through an emphasis on education. To achieve that goal, the IFEM published manuscripts in 2009 and 2011 describing undergraduate (also known as "medical school") education and graduate education (also known as "residency training" or "registrar education"). The final piece of this longitudinal series is to describe post-training education. This has been traditionally known as "continuing medical education" (CME) but is perhaps more appropriately known as "continuous professional development" (CPD).

\section{INTRODUCTION}

During the last fifty years, EM has emerged as an independent medical specialty in many countries worldwide. Medical school curricula, ${ }^{1}$ specialty training, ${ }^{2}$ and research have all blossomed in various forms around the globe. These formal curricula are well defined, yet they represent only a small portion of the active life of a physician's medical practice. However, the criteria that define the requirements for an emergency physician's education that occur after formal training have not been well delineated. This manuscript describes the current status of CPD in international EM and provides guidelines for the establishment of a CPD standard for EM.

\section{The case for post-training education}

In the many countries that have embraced EM, the emphasis has been on specialty training. The majority of current training programs range from 3-8 years in duration. They involve didactic and clinical training that produces graduates with the minimum skills and knowledge required for the independent practice of EM. While each country has somewhat different standards for the independent practice of EM, there is much overlap. ${ }^{2}$

The public, payers and regulators have recently become very interested in what happens to physicians after they complete their formal training. The challenge for physicians is to both maintain competence after specialty training and to acquire new knowledge and skills. CME has been defined as "ongoing medical education." However, CME may not be adequate. The concept of skill development post-specialty-training is known as "continuous professional development" (CPD). Developing robust and meaningful CPD is a challenge that is not unique to EM.

From the *Indiana University, Indianapolis, IN; †University of Maryland School of Medicine, Baltimore, MD; $\neq$ University of Leicester, United Kingdom; §The Alfred Hospital Emergency and Trauma Centre, Monash University, Melbourne, Australia; đUniformed Services University of the Health Sciences, Bethesda, MD; \|University of Western Sydney, Australia; **Australian Government Department of Health, Canberra, Australia; ††Australian National University Medical School, The Canberra Hospital, Canberra, Australia; and ¥¥Akron General Medical Center, Northeast Ohio Medical University, Akron, $\mathrm{OH}$

Correspondence to: Dr. Cherri Hobgood, 720 Eskenazi Ave, 5/3 FOB Emergency Medicine 3rd floor, Indianapolis, IN 46202; E-mail: chobgood@ iu.edu 
In this manuscript, we describe characteristics of CPD that are applicable to EM around the world.

\section{The case for CME}

In most countries with well-developed medical disciplines, physicians are required to undergo $\mathrm{CME}$ according to requirements set by national regulatory agencies. CME activities can be divided into broad categories: traditional or sometimes called live (such as lectures and seminars that involve face-to-face meetings); review or group activities and case conferences; written or permanent education materials that sometimes include tests or written assignments; ${ }^{3}$ and newer technologies such as audio, video, or the Internet. Much CME is now accomplished with online offerings. CME is typically based on an hour system where one hour of education activity equates to one CME credit.

The amount of time that physicians engage in $\mathrm{CME}$, i.e., the post-formal-training phase of their career, is the longest of any of the educational opportunities. During the post-training career phase, physicians cite a variety of reasons for seeking CME. Most commonly, physicians pursue $\mathrm{CME}$ to maintain competence and improve patient care. Physicians feel strongly that participating in $\mathrm{CME}$ activities assists them in maintaining competence and gaining new knowledge and skills. ${ }^{4}$

Whilst formalized CME is one method of maintaining current medical knowledge, a comprehensive review of the literature performed by the Agency for Healthcare Research and Quality (AHRQ) demonstrates that CME is only modestly effective at changing physician knowledge, attitudes, skills, and practice behavior. It is even less successful at changing clinical practice outcomes. ${ }^{5}$ Two other large meta-analyses of CME demonstrate that CME modalities range in effectiveness depending upon intervention type. In particular, it is rare for lecture-style-only didactics to be effective in changing practice. ${ }^{6,7}$

\section{The case for transition from CME to CPD}

In order to practice effectively throughout their professional lives, physicians must remain up-to-date. This entails engaging in some form of continuing education. Many medical educators believe that $\mathrm{CME}$ may be the only component necessary for CPD. CME programs can provide needed clinical updates and an opportunity for additional education, training, and sub-specialization. ${ }^{8}$

To deliver the highest-quality patient care, the content of CME must be directed toward enhancing skills and competencies. Clinical skills, a theoretical knowledge of organizational team building and leadership, communication, medical ethics, teaching, research, and administration are all areas within which the individual physician must learn to remain an effective care provider.

To meet that goal, many educators have suggested that required CME should evolve from the current practice of counting hours of CME participation to recognizing physician achievement in knowledge, competence and performance. ${ }^{9}$ Medical boards should require valid and reliable assessment of physicians' learning needs. There should be a collaboration between physicians and CME providers to ensure that legislatively mandated $\mathrm{CME}$ achieves the greatest possible benefit for physicians and patients.

Despite the broad range of CME aimed at educating practicing physicians, researchers have found that in actual practice physicians commonly overuse, underuse or misuse therapeutic and diagnostic interventions. CME may therefore not suffice to significantly narrow the gap between clinical practice and current evidence. ${ }^{10}$

The limitations of CME have led to the concept of CPD. New medical knowledge should transform concepts through research into clinical practice. $\mathrm{CME}$ alone is no longer enough for the provider to maintain cutting edge proficiency. The medical profession must enter into a program of CPD to be able to incorporate new knowledge into clinical practice.

$\mathrm{CPD}$ is a process of lifelong learning. There are several reasons for CPD: to improve skills that provide better patient care, to improve non-clinical skills, and to satisfy employers or regulators. CPD should include an ongoing commitment to continuing professional development as the major component of the process. ${ }^{3}$

The critical focus of CPD is to deliver educational materials to practicing physicians, no matter when they completed training, such that they can incorporate new knowledge into their practice. Medical science and technology are always changing. New life-saving ideas are always being sought and disseminated. Successful physicians must incorporate these into their professional development. 
In addition to new medical knowledge, new ethical demands and economic developments continually confront the medical profession. This challenges the individual physician to assume new roles for which the doctor's original training may not have prepared him or her. The evolving role of quality assurance and changes to health care delivery systems are also significant reasons why physicians must transition from CME to the more active educational program of CPD.

\section{Effectiveness of CPD}

Although the evidence for CPD effectiveness is limited, where it exists it covers a number of dimensions. There has been a limited focus specifically on CPD in $\mathrm{EM} ;{ }^{11-18}$ however, most medical CPD research is generally applicable to any medical specialty. There is a reasonably strong association between certified assessment of training and future clinical performance. ${ }^{19,20}$ This mainly relates to certification of specialist training, but could be extrapolated to include certification related to CPD. ${ }^{21}$ There is evidence that emergency physicians in the USA who participate in Maintenance of Certification maintain the same level of performance on their every decade test of medical knowledge. ${ }^{22}$ There is a lack of direct evidence on the effect of any particular regulatory regime (certification by examination, records and audit of participation, etc.) on CPD participation or clinical performance. ${ }^{23}$ There is evidence that participation in CPD has a positive effect on knowledge acquisition and retention, though the evidence is weaker in terms of clinical outcomes. ${ }^{5,6,24-26}$ There is evidence of an association between maintenance of certification and some quality of care markers. ${ }^{25}$

In relation to the question of which CPD formats are more effective, a major review of CPD in the USA and Canadian context recommended the use of multimedia, multiple instructional techniques, and multiple exposures to CPD content. ${ }^{5}$ Whilst there is evidence that unsolicited print materials are generally ineffective, ${ }^{27}$ the use of single live media versus multiple media is not clear, though either is superior to print. Whilst it seems intuitive that multiple exposures versus a single exposure would be superior, the evidence is weak, with either method leading to positive results. Specifically with respect to simulation as an educational tool, simulation has been used widely in undergraduate and graduate medical education (GME) programs, and training of personnel working in inter-professional teams of health care professionals. However, surprisingly, it has not been widely implemented in CPD programs in EM.

There is evidence that medical simulation is an effective learning tool. A best evidence medical education (BEME) systematic review identified 10 conditions that may facilitate learning in high-fidelity medical simulations, including the provision of feedback during the learning experience, learners engaging in repetitive practice, and the integration of simulation into the curriculum. ${ }^{28}$ Furthermore, the use of simulation is consistent with best practices in CPD, such as mastery learning and deliberate practice, ${ }^{29}$ although there is very little evidence specific to the CPD context. More recently, in situ simulation has emerged as a feasible educational strategy for facilitating learning in a safe environment in the context of the local environment. ${ }^{30}$ It has the potential to improve individual, team, unit, and organizational learning. However, there is little evidence relating to its effectiveness in the transfer of learning into actual improvements in clinical practice, and ultimately, patient outcomes. While the evidence on simulation effectiveness remains lacking in clinical outcomes and skill development, there is at least modest evidence to support its use in teamwork training and critical incident communication, two essential competencies for EM.

Given the current state of knowledge on the effectiveness of CPD, medical specialty organizations should be flexible when developing CPD programs. The programmatic rationale and justification must be transparent. CPD will be most successful when it is linked to needs analyses, assessment, and accreditation. There should be multiple offerings that account for the many differences amongst adult learners. Any CPD program should be designed to meet the needs of physicians and the community they serve.

\section{Continuous Professional Development for Emergency Medicine}

Only a small number of countries with EM specialty training programs have developed specific educational requirements for post-training CPD. There is tremendous worldwide variation in EM CPD programs. There are no standard, recognized international curricula for EM CPD.

Once training is complete and an emergency physician (EP) meets criteria for national certification (after completing both his or her undergraduate and 
graduate curricula), the EP must continue to evolve as a professional. That evolution must be based on individual needs, identified by practice assessment, as well as external needs, e.g., those of the specialty, and the local and national system of care delivery. Globally, external needs must be driven by the appropriate regulatory body. This will differ from country to country. Each EM organization must work with its own regulatory agencies to decide what role EM will play in the country's health care program. Any EM-specific objective must be delineated and carefully detailed by all stakeholders. The resulting CPD curriculum should reflect these objectives and be designed to accomplish them. The CPD program can then be implemented at the national and local level. For countries where resources are limited, a national approach to high-cost curricular needs is desired. In that way, scant resources can be used to assist all EPs to achieve the goals of CPD.

CPD is important for the career evolution of all EPs. For academic-based EPs, the metrics used to judge success are set by the institution (usually the university or equivalent), and should be transparent and readily accessible. Issues such as teaching time, teaching evaluations, scholarly publications, funding, and national and international presentations are typically important, but may not represent all items needed to achieve institutional advancement. Within this milieu, the exact value of each component varies by university and across countries. A successful professional development plan involves matching one's personal goals and achievements with those valued by the university or institution for which one works. Successful professional development in an academic practice is measured by promotion and tenure. Recognition is based on the candidate's record of performance in the areas of teaching, research, and service. Most universities highly value scholarship. The number of scholarly publications is counted and each manuscript is judged by how frequently it is cited by other authors. Extramural funding is frequently recognized as an external validation of quality. Faculty members must also maintain a list of all courses, the number of students taught, and an estimate of total student contact hours. Teaching quality is documented through student feedback and peer evaluation. Evidence of teaching awards or publications related to educational efforts constitutes excellent evidence of activity worthy of academic promotion. If one meets the criteria, this is recognized with academic titles demonstrating advancing rank: assistant, associate, then full professor.

In non-academic careers, the criteria for success are not as clear as in academia. They may include personal, employer, hospital or community goals. Career development in this arena is focused on an adaptation to an ever-changing practice environment. Successful EPs are constantly acquiring new skills. To facilitate this growth, a program of professional development must be planned. Attention should be paid to both short-term and long-term needs. Knowledge and skills can be acquired by self-instruction, short courses, attending seminars given by professional organizations, or by enrolling in formal courses of instruction sponsored by universities or business schools. A large amount of information is always available at a library or on the Internet. Areas of development might include becoming a clinical content expert (e.g., airway, wound care, ultrasound), a sub-specialty (e.g., toxicology, pediatric, emergency medical services, hyperbaric, palliative care, critical care), administrative (e.g., business, regulatory, leadership, professional societies), and research.

Mentors are also important in helping physicians develop their professional skills. A mentor could be a more experienced colleague, someone who has successfully traversed the same political, university or employment environment, a coach, or someone who opens doors when needed. It is true that successful people, including EPs, have much to learn from others.

\section{IFEM and EM CPD}

It is the desire of the IFEM that this manuscript be used to help develop EM CPD programs throughout the world.

The development of a robust CPD program requires the emergency physicians of a country to be actively involved in the process. The initial establishment of a program requires a needs assessment to identify post-training development gaps and opportunities. This must include both physician and regulatory input. Representative emergency physicians should meet with the regulatory body and discuss national needs. A working group could take the agreed-upon objectives and develop a CPD curriculum. This plan would be easiest to implement if ratified by all parties involved. EM educators could then develop a step-by-step curriculum to accomplish the educational goals. Whether they are called objectives, milestones, competencies, or 
Table 1. Comparison of Current National CME/CPD Programs

EMERGENCY MEDICINE CPD STRUCTURE BY COUNTRY

\begin{tabular}{|c|c|c|c|c|}
\hline COUNTRY & CME/CPD PROGRAM & DESCRIPTION & ACTIVITIES & MORE INFORMATION \\
\hline \multirow[t]{5}{*}{ USA } & $\begin{array}{l}\text { American Board of Emergency } \\
\text { Medicine } \\
\text { (ABEM) } \\
\text { Board Certification }{ }^{1}\end{array}$ & $\begin{array}{l}\text { Physicians who successfully complete each of these } \\
\text { steps are certified as diplomates of the American Board } \\
\text { of Emergency Medicine (ABEM). Certification is for a } \\
\text { period of } 10 \text { years. }\end{array}$ & $\begin{array}{l}\text { There are three steps to achieve Emergency } \\
\text { Medicine certification after completing EM } \\
\text { specialty training: } \\
\text { - } \text { applying and credentialing, } \\
\text { taking and passing a qualifying } \\
\text { examination, } \\
\text { - taking and passing an oral certification } \\
\text { examination. }\end{array}$ & www.abem.org \\
\hline & $\begin{array}{l}\text { ABEM } \\
\text { Maintenance of Certification }\end{array}$ & $\begin{array}{l}\text { To maintain certification beyond the expiration date of the } \\
\text { certificate, diplomates must participate in the ABEM } \\
\text { Maintenance of Certification (MOC). } \\
\text { This process is continuous and requires yearly activities } \\
\text { and educational requirements to qualify to take a } \\
\text { recertification exam every } 10 \text { years after initial board } \\
\text { certification. }\end{array}$ & $\begin{array}{l}\text { The ABEM MOC program is based on four } \\
\text { components: } \\
\text { - Professional Standing } \\
\text { - } \frac{\text { Lifelong Learning and Self-Assessment }}{\text { (LLSA) }} \\
\text { - Assessment of Cognitive Expertise } \\
\text { Assessment of Practice Performance } \\
\text { (APP) }\end{array}$ & www.abem.org \\
\hline & $\begin{array}{l}\text { American Osteopathic Board of } \\
\text { EM (AOBEM) } \\
\text { Board Certification }{ }^{1}\end{array}$ & $\begin{array}{l}\text { Physicians who successfully complete each of these } \\
\text { steps are certified as diplomates of the American } \\
\text { Osteopathic Board of Emergency Medicine (AOBEM). } \\
\text { This is equivalent to ABEM. Certification is for a period } \\
\text { of } 10 \text { years. }\end{array}$ & $\begin{array}{l}\text { After completing an osteopathic EM } \\
\text { residency, the candidate completes } \\
\text { written, oral and clinical examinations. }\end{array}$ & www.aobem.org \\
\hline & $\begin{array}{l}\text { American Osteopathic Board of } \\
\text { EM (AOBEM) } \\
\text { Continuous Certification }^{1}\end{array}$ & $\begin{array}{l}\text { To maintain certification beyond the expiration date of the } \\
\text { certificate, diplomates must participate in the AOBEM } \\
\text { Continuous Certification in EM process (CCEM). This } \\
\text { process is continuous and requires yearly activities and } \\
\text { educational requirements to qualify to take a } \\
\text { recertification exam every } 10 \text { years after initial board } \\
\text { certification. }\end{array}$ & $\begin{array}{l}\text { The CCEM process includes continual } \\
\text { components that occur throughout a } 10 \\
\text { year cycle: } \\
\text { - Yearly exams based on readings } \\
\text { - Yearly CME requirements } \\
\text { - Continuous licensing and credentialing } \\
\text { - Formal recertification exam at } 10 \text { years }\end{array}$ & www.aobem.org \\
\hline & State MD Licensure & Basic CME/CPD requirements for every physician & $\begin{array}{l}\text { Varies by state; between } 50-200 \text { hours } \\
\text { every two years of CME/CPD-approved } \\
\text { activities: } \\
\text { - Conferences, lectures, courses } \\
\text { - Research } \\
\text { - Teaching } \\
\text { - Other }\end{array}$ & \\
\hline
\end{tabular}

- Other 
Table 1. (Continued)

N $\quad$ EMERGENCY MEDICINE CPD STRUCTURE BY COUNTRY

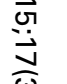

COUNTRY CME/CPD PROGRAM DESCRIPTION ACTIVITIES MORE INFORMATION

United College of Emergency Continuing professional development (CPD) is the

Kingdom Medicine (CEM) ${ }^{1} \quad$ process by which individual doctors keep themselves

up- to-date and maintain the highest standard of

Examples of evidence that would be

www.collemergencymed.ac.uk professional practice.

required for CPD are as follows:

CPD should also support specific changes in practice.

Normally, credits given by Colleges/Faculties for CPD should be based on one credit equating to one hour of educational activity (or an equivalent measure of educational activity).

- Attendance certificates at educational courses/meetings

- e-learning self-assessment certificates

- Attendance at examinations as an

Examiner

- Programs of meetings if there are no certificates

The minimum required should be an average of 50 credits per year. Credits for un-timed activities such as writing, reading and e-learning should be justified by the participant or should be agreed upon between the provider(s) and College/Faculty directors of CPD. ${ }^{1}$

- Copies of proposals written for specific

committees within the Trust

- Protocols written

- Copies of papers and abstracts

presented

- Copies of the Advanced Life Support course programs, when an instructor showing contribution to the teaching program

- Research grants

- List of papers refereed

- Programs of courses on which you have lectured

- Self-accreditation with documented reflective learning

- All documentary evidence relating to CPD can be saved to the CEM website on an individual area for convenience. 


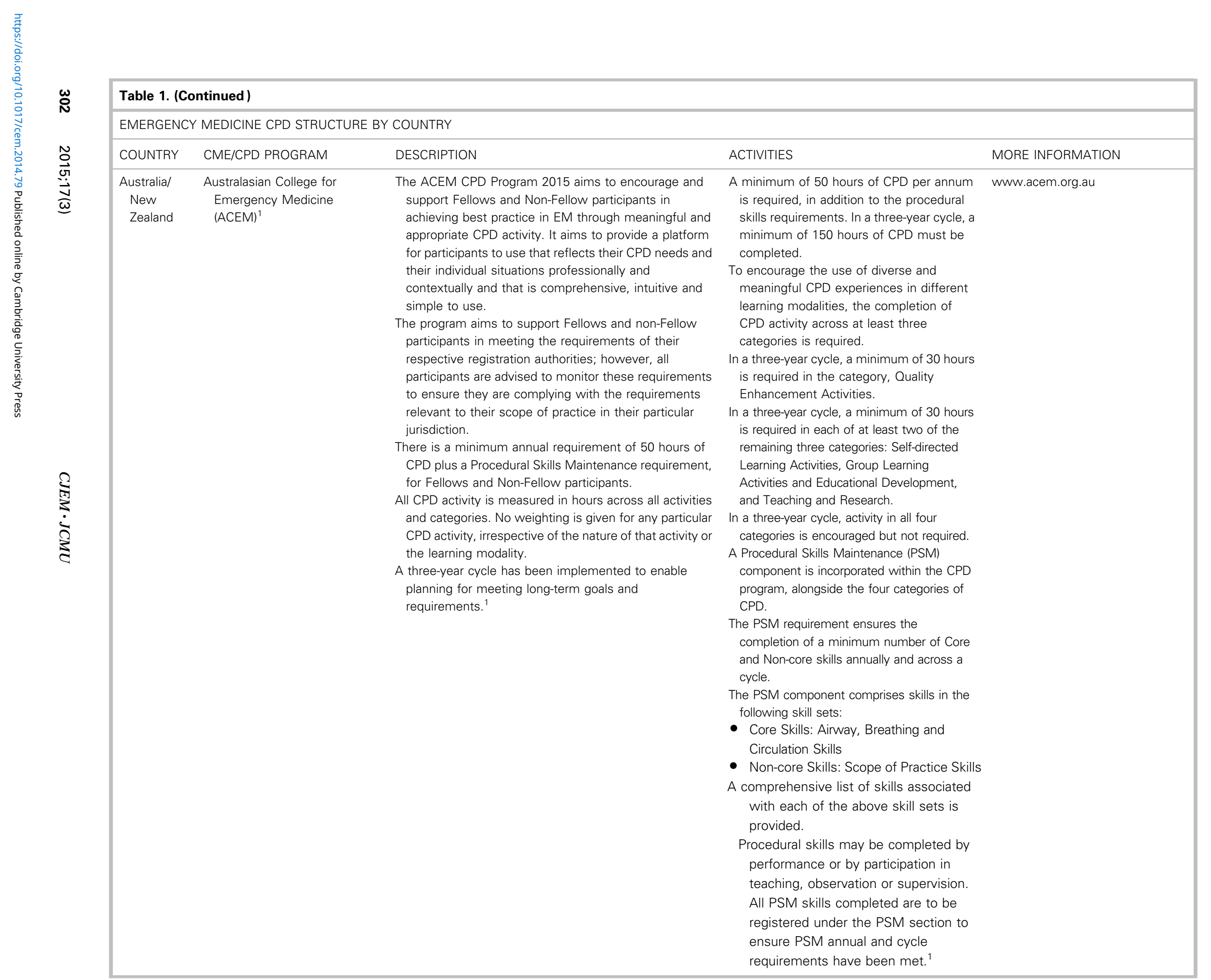




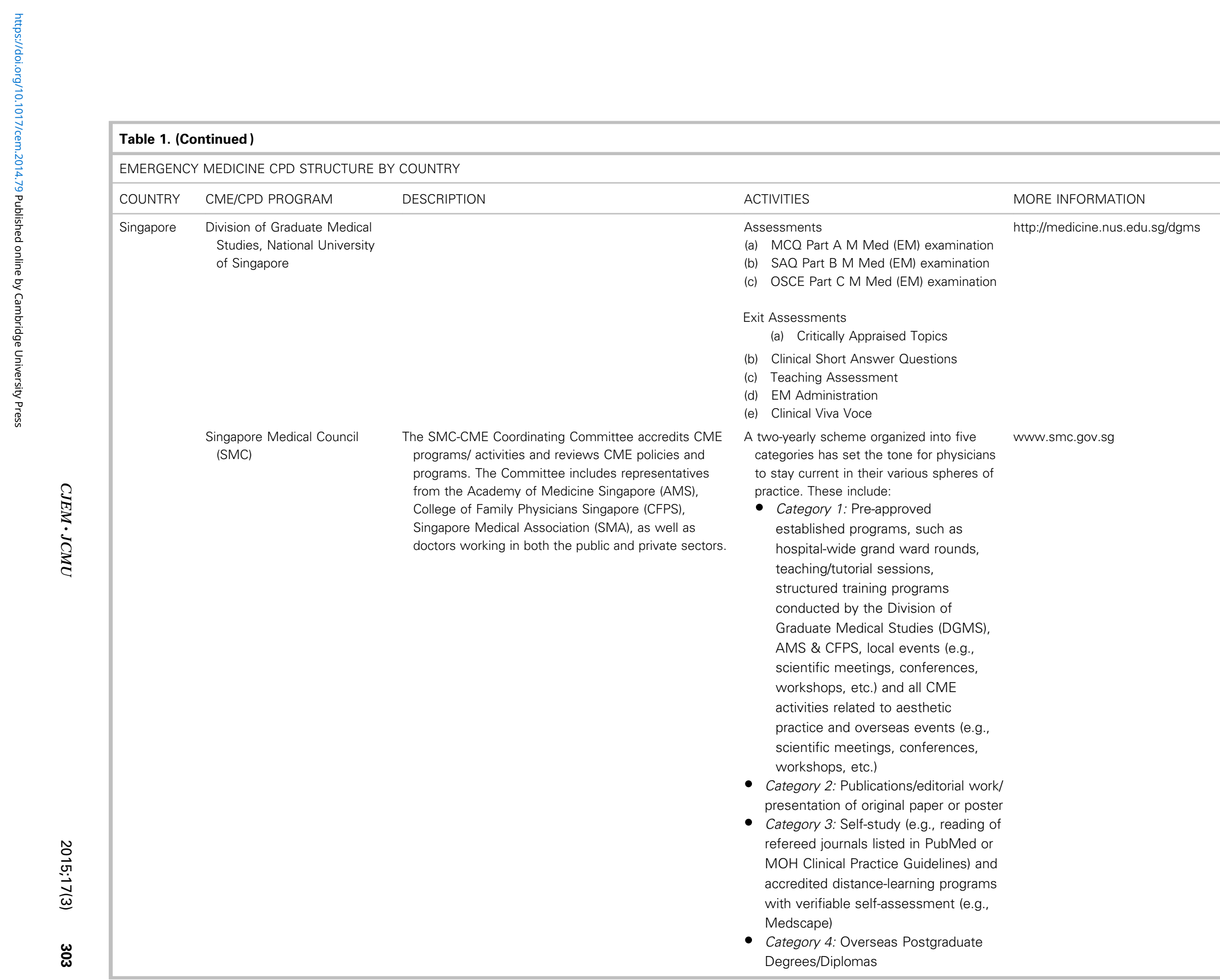




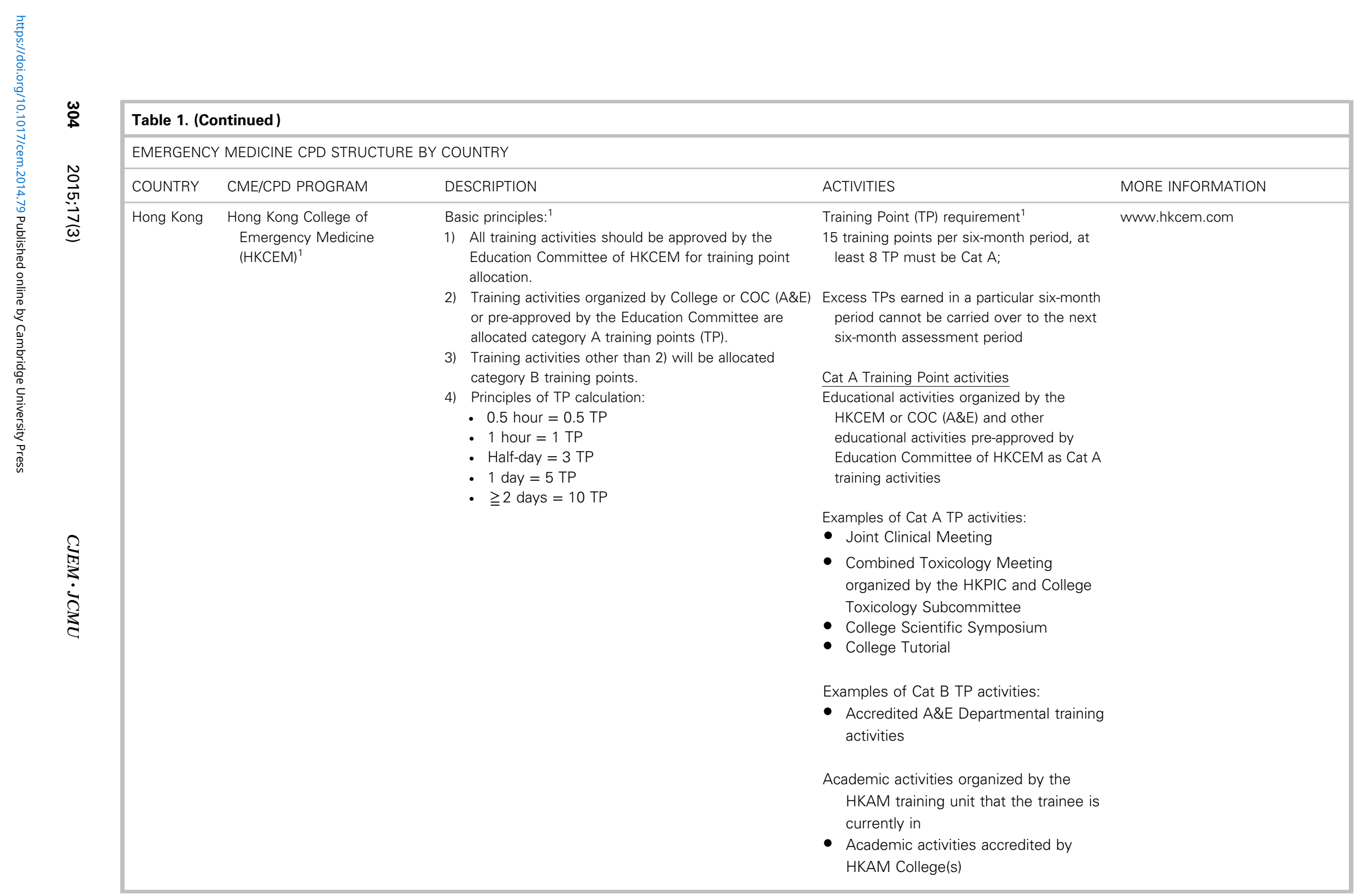




\section{Table 2. IFEM curriculum framework for Continuing Professional Development in Emergency Medicine}

INITIAL POINTS TO CONSIDER

- CPD programs are ultimately designed to change and improve behavior of emergency physicians and medical professionals, in order to achieve the safest, most effective and highest quality emergency medicine clinical practice for our patients.

- CPD programs for EM should be designed and developed by your national EM society or college, or another appropriate body that can maintain sufficient planning, oversight, funding, administration and improvement of the CPD curriculum and its implementation.

- CPD programs should provide updates on the most important, pertinent, efficacious and salient changes to EM education and practice for clinicians and educators, especially for those who may have completed their formal specialist education in the past.

\section{STRUCTURE}

- CPD curricula and structures should be part of the continuum of EM education.

- Many existing CPD curricula are based on an hours system, where one hour of educational activity equates to one CPD credit or CPD hour, with some further qualifier or multiplier of these hours deemed superior.*

- CPD educational activities tend to be divided into three broad categories:

- "live" or "external activities"

- Lectures, seminars, courses, videos, audio recordings, presentations, meetings, etc.

- "internal activities"

- Peer-review or group activities, case conferences, journal clubs, grand rounds, peer consultation, and other practice-based activities.

- "enduring activities"

- Written, permanent or other materials such as tests, writing assignments, computer-based or web-based materials, printed materials, curricula development, self-learning activities, and other assessment processes*

CONTENT

- CPD curricula MUST align with all other local and national CME requirements, and SHOULD align with other local, national and regional CME/CPD curricula, whenever feasible or applicable.

- CPD curricula should be free from influence from corporate or other private industries.

- Elements to include in the CPD curriculum can include but are not limited to the following examples:

- Clinical EM topics: basic and advanced airway management, advanced EKG and EM cardiology topics, EM ultrasound, advances in critical care, topics in pediatric EM, toxicology emergencies, procedures in EM, and modular courses such as APLS, ACLS, etc.

- Academic and Administrative EM topics: Academic and teaching principles in EM, running an EM residency/specialist training program, measuring and improving quality in EM, administration and management principles in the emergency department, research in EM, etc.

- Professional and ethical EM topics: Patient safety in EM, models of clinical and professional practice, economic and financial aspects of EM, ethical considerations in EM, specialty development, medical-legal aspects of EM, professional, social and personal skills, burnout and health maintenance issues, etc.

\section{IMPLEMENTATION}

- Establishment of numbers of hours necessary for maintenance of professional standards/CPD, based on the specific needs of your EM system/country/region

- Most countries require basic minimums of between 50-200 CPD hours every 1-2 years, and encourage as many CPD hours as possible.

- Multipliers and modifiers of the number of hours can be based on strength, difficulty, and efficacy of given CPD activities.

- Example: hours spent on teaching, curriculum development, peer review, or policy formation may be given more value than hours spent attending lectures, watching videos, attending conferences, etc. 
- Solicitation, selection, evaluation, and re-evaluation of teaching faculty and teaching activities, based on overall EM curriculum needs and on local/regional needs, and based on updates and changes in overall and local EM practice, science and evidence

- Construction of an overall structure for CPD activities, taking into account calendars, schedules, location, cost, feasibility, and attendance

- Determination of policies and procedures for certification, re-certification, remediation, and penalties

\section{ASSESSMENT}

- Consideration for methods to motivate practitioners to engage in CPD activities, including requirements, rewards, penalties and/or sanctions

- Methods for recording the numbers of hours spent attending educational activities, lectures, conferences, seminars, etc.

- Methods for recording the numbers of hours spent attending peer-review or group activities, case conferences, journal clubs, grand rounds, peer consultation, and other practicebased activities

- Methods for recording the numbers of hours spent on tests, writing assignments, computer-based or web-based materials, printed materials, curricula development, self-learning activities, and other assessment processes

- Construction of peer-review, auditing, mediation and sanction for those not meeting established and agreed-upon CPD requirements

IMPROVEMENT

- Evaluation, review and modification of on-going and planned CPD programs, courses and activities

- Monitoring and evaluation of corporate and industry influence on CPD programs

- On-going evaluation of the entire CPD program's effect on changes in clinical practice

EXAMPLES OF CPD ELEMENTS THAT ARE IN COMMON WITH MOST EXISTING EM CPD SYSTEMS:

- Hours-based system for CPD activities, with local/national/regional requirements for maintenance of professional standards

- Inclusion of topics in many fields deemed important and necessary for CPD, including clinical, academic, administrative, professional, ethical and financial areas

- Use of multiple modalities for CPD activities, including live/lecture activities, internal/group activities and enduring/written activities (although in many places, most CPD activities are still too-heavily lecture- or conference-based)

- Establishment, assessment and requirements of CPD activities to maintain professional practice (although some CPD programs still only require basic minimums)

*Cathy Peck, Martha McCall, Belinda McLaren, Tai Rotem. "Continuing medical education and continuing professional development: international comparisons." BMJ 2000;320:432-5. 
proficiencies, the desired outcome would be a series of continuing educational activities and training experiences that would help the nation's emergency physicians evolve and continue to provide the best possible care for the nation's patients. The IFEM supports the integration of medical simulation into a CPD program for specialists in EM. As a learning tool within a CPD program, it may have the potential to facilitate learning in complex environments, such as the ED setting.

A CPD program should build on a physician's training. Ideally there should be integration with medical school and specialty training. Lifelong learning across such disparate elements is called "vertical integration." To vertically integrate, all three educational phases must cooperate and ideally achieve agreement on a longitudinal, integrated curriculum. This would then become a road map for specialty training, physician education, and performance across an entire career. Currently, we are aware of a few countries that have a common theme and easy transitions between the three educational phases. At this time, no country has achieved complete vertical integration. A partial listing of national CPD programs is presented in Table 1 .

A number of nations have some form of mandatory requirements for $\mathrm{CME}$. The process of CPD should include CME and every effort should be made to align the requirements to the needs of the practicing physician. CPD should be part of a continuum of training, building on GME in a vertically integrated fashion. There should be a clear relationship between the GME and CPD curricula. There should also be a clear relationship between patient care needs and CPD. A comprehensive IFEM curriculum framework is provided in Table 2.

\section{CPD challenges and opportunities}

The CME/CPD world is more heterogeneous and less structured in most jurisdictions than either undergraduate or graduate medical education. Undergraduate and graduate medical education focus primarily on medical knowledge and the development of the fundamentals of practice skills. A successful CPD program will integrate medical school, GME, and CPD into a continuum of lifelong learning on a diverse range of topics more expansive than medical knowledge. In addition to medical knowledge, CPD must encompass other topics into the curricula, such as ethics, technology, organizational change management and knowledge translation. This may prove to be especially difficult since most physicians have rudimentary-if anytraining in business or management. Since most EM faculty are not experts nor prepared to teach these subjects, the learner must seek this content elsewhere. Teaching resources may not be easily available in the local environment. Organizations such as the IFEM may provide support in this domain.

Whilst IFEM does not mandate CPD, there are core principles that IFEM endorses: every EP should evolve in the multiple domains that are required for practice advancement; patient care should evolve according to the best available evidence; and there is a set of basic core EM knowledge, skills, and attitudes that define the discipline regardless of the location of practice. There is individual and national practice variation and every country should establish its own longitudinal EM curriculum that integrates content from the undergraduate (medical school) and graduate (formal specialty training) as well as professional development (post-training education) career phases.

\section{SUMMARY}

EPs must learn new skills and evolve as their careers develop. How individuals evolve their professional practice requires personal insight into areas of deficiency and an understanding of the growth required by their local and national regulatory agencies. CPD should be provided based upon a shared vision of improving the care delivered to the patient at the bedside. While the design and implementation of CPD curricula can and should vary by nation, there are core EM specialty principles and practices that are common to all EM CPD. Matching self-development with the overarching objectives of the nation and the discipline will result in long-term care improvement for the nation's patients and career satisfaction for the EP.

Acknowledgments: The authors are publishing on behalf of the Core Curriculum and Education Committee for the International Federation for Emergency Medicine.

\section{SUPPLEMENTARY MATERIAL}

To view supplementary material for this article, please visit http://dx.doi.org/10.1017/cem.2014.79 


\section{REFERENCES}

1. Hobgood C, Anantharaman V, Bandiera G, et al. International Federation for Emergency Medicine model curriculum for medical student education in emergency medicine. C7EM 2009;11(4):349-54.

2. Hobgood C, Anantharaman V, Bandiera G, et al. International Federation for Emergency Medicine model curriculum for emergency medicine specialists. CFEM 2011;13(2): 109-21.

3. Peck C. Continuing medical education and continuing professional development: international comparisons. BM7 2000;320(7232):432-5.

4. Gruppen LD, Wolf FM, van Voorhees C, Stross JK. Dimensions of Motivation for Continuing Medical Education of Primary Care Physicians. Eval Health Prof 1986;9(3): 305-16.

5. Marinopoulos SS, Dorman T, Ratanawongsa N, et al. Effectiveness of continuing medical education. Evid Rep Technol Assess 2007;149:1-69.

6. Davis DA, Thomson MA, Oxman AD, et al. Evidence for the effectiveness of CME. A review of 50 randomized controlled trials. $7 A M A$ 1992;268(9):1111-7.

7. Oxman AD, Thomson MA, Davis DA, et al. No magic bullets: a systematic review of 102 trials of interventions to improve professional practice. CMA7 1995;153(10):1423-31.

8. WFME. World Federation for Medical Education document, "Continuing Professional Development of Medical Doctors", WFME Global Standards for Quality Improvement. Denmark: University of Copenhagen; 2003.

9. Davis D, Bordage G, Moores LK, et al. The science of continuing medical education: terms, tools, and gaps: effectiveness of continuing medical education: American College of Chest Physicians Evidence-Based Educational Guidelines. Chest 2009;135(3 Suppl):8s-16s.

10. Miller SH, Thompson JN, Mazmanian PE, et al. Continuing medical education, professional development, and requirements for medical licensure: a white paper of the Conjoint Committee on Continuing Medical Education. 7 Contin Educ Health Prof 2008;28(2):95-8.

11. Jones JH, Smith-Coggins R, Meredith JM, et al. Lifelong learning and self-assessment is relevant to emergency physicians. 7 Emerg Med 2013;45(6):935-41.

12. Dent AW, Asadpour A, Weiland TJ, et al. Australasian emergency physicians: a learning and educational needs analysis. Part one: background and methodology. Profile of FACEM. Emerg Med Australas 2008;20(1):51-7.

13. Paltridge D, Dent AW, Weiland TJ. Australasian emergency physicians: a learning and educational needs analysis. Part two: confidence of FACEM for tasks and skills. Emerg Med Australas 2008;20(1):58-65.

14. Weiland TJ, Dent AW, Paltridge D. Australasian emergency physicians: a learning and educational needs analysis. Part three: participation by FACEM in available CPD: what do they do and do they like it? Emerg Med Australas 2008;20(2):156-63.

15. Dent AW, Weiland TJ, Paltridge D. Australasian emergency physicians: a learning and educational needs analysis. Part Four: CPD topics desired by emergency physicians. Emerg Med Australas 2008;20(3):260-6.
16. Dent AW, Weiland TJ, Paltridge D. Australasian emergency physicians: a learning and educational needs analysis. Part five: barriers to CPD experienced by FACEM, and attitudes to the ACEM MOPS programme. Emerg Med Australas 2008;20(4):339-46.

17. Dent AW, Paltridge D, Weiland TJ. Australasian emergency physicians: A learning and educational needs analysis. Part six: differences in confidence, exposure to learning and expressed learning needs by subgroups of Australasian emergency physicians. Emerg Med Australas 2008;20(4):347-56.

18. Schrock JW, Cydulka RK. Lifelong learning. Emerg Med Clin N Am 2006;24(3):785-95.

19. Rhodes RS, Biesten TW, Ritchie WP, et al. Continuing medical education activity and American Board of Surgery examination performance. 7 Am Coll Surg 2003;196(4): 604-9; discussion 10, author reply 10.

20. Bordage G, Carlin B, Mazmanian PE. Continuing medical education effect on physician knowledge: effectiveness of continuing medical education: American College of Chest Physicians Evidence-Based Educational Guidelines. Chest 2009;135(3 Suppl):29s-36s.

21. Lipner R, Song H, Biester T, et al. Factors that influence general internists' and surgeons' performance on maintenance of certification exams. Acad Med 2011;86(1):53-8.

22. Marco CA, Counselman FL, Korte RC, et al. Emergency physicians maintain performance on the American Board of Emergency Medicine Continuous Certification (ConCert) examination. Acad Emerg Med 2014;21(5):532-7.

23. Lowe MM, Bennett N, Aparicio A. The role of audience characteristics and external factors in continuing medical education and physician change: effectiveness of continuing medical education: American College of Chest Physicians Evidence-Based Educational Guidelines. Chest 2009;135 (3 Suppl):56s-61s.

24. Wenghofer EF, Marlow B, Campbell C, et al. The relationship between physician participation in continuing professional development programs and physician inpractice peer assessments. Acad Med 2014;89(6):920-7.

25. Holmboe ES, Wang Y, Meehan TP, et al. Association between maintenance of certification examination scores and quality of care for Medicare beneficiaries. Arch Intern Med 2008;168(13):1396-403.

26. Davis D, O'Brien MA, Freemantle N, et al. Impact of formal continuing medical education: do conferences, workshops, rounds, and other traditional continuing education activities change physician behavior or health care outcomes? $7 A M A$ 1999;282(9):867-74.

27. Davis D, Galbraith R. Continuing medical education effect on practice performance: effectiveness of continuing medical education: American College of Chest Physicians EvidenceBased Educational Guidelines. Chest 2009;135(3 Suppl): 42s-8s.

28. Issenberg SB, McGaghie WC, Petrusa ER, et al. Features and uses of high-fidelity medical simulations that lead to effective learning: a BEME systematic review. Med Teach 2005;27(1):10-28.

29. McGaghie WC, Siddall VJ, Mazmanian PE, et al. American College of Chest Physicians H, Science Policy C. Lessons for continuing medical education from simulation research in undergraduate and graduate medical education: 
effectiveness of continuing medical education: American College of Chest Physicians Evidence-Based Educational Guidelines. Chest 2009;135(3 Suppl):62S-8S.

30. Rosen MA, Hunt EA, Pronovost PJ, et al. In situ simulation in continuing education for the health care professions: a systematic review. 7 Contin Educ Health Prof 2012;32(4): 243-54.

31. CANADA TCOFPO. Continuing Professional Development (CPD). Available at http://www.cfpc.ca/CPD/ (accessed September 25, 2014). 